\section{Continuous Glucose Monitoring and Use of Alternative Markers To Assess Glycemia in Chronic Kidney Disease}

Diabetes Care 2020;43:2379-2387 | https://doi.org/10.2337/dc20-0915
Leila R. Zelnick, ${ }^{1,2}$ Zona O. Batacchi, ${ }^{3}$ Iram Ahmad, ${ }^{4,5}$ Ashveena Dighe, ${ }^{1}$ Randie R. Little, ${ }^{6}$ Dace L. Trence, ${ }^{7}$ Irl B. Hirsch, ${ }^{7}$ and lan H. de Boer ${ }^{1,2,8}$

\section{OBJECTIVE}

In chronic kidney disease, glycated albumin and fructosamine have been postulated to be better biomarkers of glycemic control than $\mathrm{HbA}_{1 \mathrm{c}}$. We evaluated the accuracy, variability, and covariate bias of three biomarkers $\left(\mathrm{HbA}_{1 \mathrm{c}}\right.$, glycated albumin, and fructosamine) compared with continuous glucose monitoring (CGM)-derived measurement of glycemia across estimated glomerular filtration rate (eGFR) in type 2 diabetes.

\section{RESEARCH DESIGN AND METHODS}

A prospective cohort study was conducted of 104 participants with type 2 diabetes, 80 with eGFR $<60 \mathrm{~mL} / \mathrm{min} / 1.73 \mathrm{~m}^{2}$ (not treated with dialysis) and 24 frequency-matched control subjects with eGFR $\geq 60 \mathrm{~mL} / \mathrm{min} / 1.73 \mathrm{~m}^{2}$. Participants wore a blinded CGM for two 6-day periods separated by 2 weeks, with blood and urine collected at the end of each $\mathrm{CGM}_{\text {period. }} \mathrm{HbA}_{1 \mathrm{c}}$, glycated albumin, and fructosamine were measured by high-performance liquid chromatographic, enzymatic, and colorimetric nitroblue tetrazolium methods, respectively.

\section{RESULTS}

Within-person biomarker values were strongly correlated between the two CGM periods ( $r=0.92-0.95)$, although no marker fully captured the within-person variability of mean CGM glucose. All markers were similarly correlated with mean CGM glucose ( $r=0.71-77)$. Compared with mean CGM glucose, glycated albumin and fructosamine were significantly biased by age, BMI, serum iron concentration, transferrin saturation, and albuminuria; $\mathrm{HbA}_{1 \mathrm{c}}$ was underestimated in those with albuminuria.

\section{CONCLUSIONS}

Glycated albumin and fructosamine were not less variable than $\mathrm{HbA}_{1 \mathrm{c}}$ at a given mean CGM glucose level, with several additional sources of bias. These results support measuring $\mathrm{HbA}_{1 \mathrm{c}}$ to monitor trends in glycemia among patients with eGFR $<60 \mathrm{~mL} / \mathrm{min} / 1.73 \mathrm{~m}^{2}$. Direct measurements of glucose are necessary to capture short-term variability.

Glycated hemoglobin $\left(\mathrm{HbA}_{1 \mathrm{c}}\right)$ is commonly used in people with diabetes to monitor long-term ( $\sim 3$ months) glycemic control. However, $\mathrm{HbA}_{1 \mathrm{c}}$ may not appropriately measure glycemic burden in those who also have chronic kidney disease (CKD), with both bias (defined as a difference in mean values) and more variability around the
${ }^{1}$ Kidney Research Institute, University of Washington, Seattle, WA

${ }^{2}$ Division of Nephrology, University of Washington, Seattle, WA

${ }^{3}$ Summit Medical Group, New Providence, NJ

${ }^{4}$ Division of Endocrinology, Banner-MD Anderson Cancer Center, Gilbert, AZ

${ }^{5}$ University of Arizona College of Medicine-Phoenix, Phoenix, AZ

${ }^{6}$ Department of Pathology and Anatomical Sciences, University of Missouri, Columbia, MO

${ }^{7}$ Division of Metabolism, Endocrinology, and Nutrition, University of Washington, Seattle, WA

${ }^{8}$ Puget Sound Veterans Affairs Health Care System, Seattle, WA

Corresponding author: Leila R. Zelnick, Izelnick@ uw.edu

Received 22 April 2020 and accepted 9 July 2020

This article contains supplementary material online at https://doi.org/10.2337/figshare.12674651.

(C) 2020 by the American Diabetes Association. Readers may use this article as long as the work is properly cited, the use is educational and not for profit, and the work is not altered. More information is available at https://www.diabetesjournals .org/content/license. 
mean possible. In CKD, red blood cell (RBC) turnover is increased, providing less opportunity for hemoglobin glycation for a given level of glycemia. Even small changes in RBC life span can affect $\mathrm{HbA}_{1 \mathrm{c}}(1)$, and consequently, $\mathrm{HbA}_{1 \mathrm{c}}$ has been shown to underestimate glycemia in those with estimated glomerular filtration rate $(\mathrm{eGFR})<30 \mathrm{~mL} / \mathrm{min} / 1.73 \mathrm{~m}^{2}$ and in those on dialysis (2,3). Anemia, which occurs commonly in CKD, and its treatment with iron supplements or erythropoietin-stimulating agents (ESAs), can affect $\mathrm{HbA}_{1 \mathrm{c}}$ levels (4-7). In addition, some studies suggest that $\mathrm{HbA}_{1 \mathrm{c}}$ differs by race (8-10), which further complicates its clinical use among the racially diverse population of patients with diabetes and CKD.

Glycated serum proteins, such as glycated albumin and fructosamine, may avoid issues related to RBC turnover and provide viable alternatives to $\mathrm{HbA}_{1 \mathrm{c}}$ as a marker of glycemia. Glycated albumin is the percentage of serum albumin to which a glucose molecule has been nonenzymatically attached, while fructosamine refers to all ketoamine linkages resulting from serum protein glycation (11). In particular, these biomarkers are not based on hemoglobin and hence, do not depend on RBC turnover $(6,12)$. In addition, with a shorter half-life than hemoglobin, glycated proteins reflect average glycemic burden of the previous 2-3 weeks and so may be better suited than $\mathrm{HbA}_{1 \mathrm{c}}$ to monitor shorter-term changes in glycemia $(2,11)$. Higher glycated albumin and fructosamine levels have both been linked to increased risk of cardiovascular outcomes and mortality as well as to other important clinical outcomes (13-16), and previous studies have suggested that glycated albumin and fructosamine may be comparable or superior to $\mathrm{HbA}_{1 \mathrm{c}}$ as a measure of glycemic control in patients treated with dialysis $(3,17-21)$. However, there are few data evaluating the performance of these alternative biomarkers compared with a gold-standard measure of glycemia in patients with eGFR $<60 \mathrm{~mL} / \mathrm{min} /$ $1.73 \mathrm{~m}^{2}$ not treated with dialysis $(2,19)$.

We prospectively enrolled 81 participants with diabetes and moderate to severe CKD (defined as eGFR $<60 \mathrm{~mL}$ / $\min / 1.73 \mathrm{~m}^{2}$ ) not treated with dialysis and 24 frequency-matched control subjects with diabetes and no CKD to undergo continuous glucose monitoring
(CGM) in two periods over an average of 12 days (22). In this article, we evaluate the accuracy, variability, and covariate bias of $\mathrm{HbA}_{1 \mathrm{c}}$, glycated albumin, and fructosamine compared with the CGM-derived measurement of glycemia, considered here to be a gold standard, across levels of GFR among people with diabetes.

\section{RESEARCH DESIGN AND METHODS}

\section{Study Design and Population}

Continuous Glucose Monitoring to Assess Glycemia in CKD (CANDY) was a prospective observational cohort study designed to characterize hypoglycemia in CKD and evaluate the performance of markers of glycemia in people with type 2 diabetes and moderate to severe CKD (22). Briefly, the study enrolled 105 participants between August 2015 and July 2017 with a clinical diagnosis of type 2 diabetes treated with sulfonylurea or insulin; 81 of these participants had moderate to severe CKD (eGFR 6 to $<60 \mathrm{~mL} / \mathrm{min} / 1.73 \mathrm{~m}^{2}$ ), and 24 control subjects (eGFR $\geq 60 \mathrm{~mL} / \mathrm{min} / 1.73 \mathrm{~m}^{2}$ ) were frequency matched by age, duration of diabetes, $\mathrm{HbA}_{1 \mathrm{c}}$, and use of glucose-lowering medication. Those with a history of kidney transplant, on dialysis, pregnant, currently using clinical CGM, currently being treated for cancer or with erythropoietin, unable to speak English, or $<18$ years of age were excluded from the study.

Participants wore a blinded CGM device for two nonconsecutive 6-day periods separated by $\sim 2$ weeks. Blood and spot urine samples were collected at the end of each CGM period; thus, biomarker measurements were separated by $\sim 3$ weeks. For this analysis evaluating the relative merits of biomarkers of glycemia compared with a CGM-based assessment of glycemia, we excluded one participant who did not have a complete set of biomarker measurements at either visit because of insufficient serum volume, for a final analytic sample of 104 participants.

The CANDY study was approved by institutional review boards of the University of Washington and the Puget Sound Veterans Affairs Health Care System. Each participant granted written informed consent.

\section{Glycemia Markers}

Biomarkers of glycemia were collected at the end of each CGM period, $\sim 3$ weeks apart. $\mathrm{HbA}_{1 \mathrm{c}}$ was measured from whole blood collected at the end of each CGM period using an NGSP network method (Tosoh G8 HPLC, Secondary Reference Laboratory, SRL 9), with long-term coefficients of variance (CVs) of $2.41 \%$ and $1.58 \%$ at levels of $5.1 \%$ and $10.4 \% \mathrm{HbA}_{1 \mathrm{c}}$. Glycated albumin was measured in serum by an enzymatic assay (Lucica GA-L kit; Asahi Kasei Pharma Corporation; kits were obtained directly from Asahi Kasei for research use only), and CVs were $4.2 \%$ and $2.1 \%$ for levels of $10.58 \%$ and $22.29 \%$, respectively. Fructosamine was measured in serum using the colorimetric nitroblue tetrazolium assay (Roche Diagnostics Corporation, Indianapolis, IN), with CVs of $4.1 \%$ and $4.0 \%$ for levels of 230 and $370 \mu \mathrm{mol} / \mathrm{L}$, respectively. Both glycated albumin and fructosamine assays were performed on the Roche cobas c 311 instrument.

\section{CGM}

Participants wore an iPro2 Professional blinded CGM Enlite sensor (Medtronic, Northridge, CA) to monitor glycemia over two nonconsecutive 6-day periods separated by $\sim 2$ weeks. Blood glucose concentrations were estimated every $5 \mathrm{~min}$ from interstitial glucose levels, with a detection range of $40-400 \mathrm{mg} / \mathrm{dL}$. Participants calibrated the CGM at least twice daily with a fingerstick capillary blood glucose using a FreeStyle Lite glucose monitor (Abbott Laboratories, Alameda, CA). Study physicians reviewed each CGM report, identifying periods of biologic implausibility (defined as evidence of CGM malfunction or marked [ $>30 \%$ ] dyssynchrony between CGM and fingerstick glucose values), which were excluded from subsequent analysis (22). Study physicians also intervened if severe hypoglycemia was noted on either CGM analysis to ensure safety of patients. The mean CGM blood glucose for each participant was calculated over all valid CGM measurements across both CGM periods and is assumed here to be a goldstandard measurement of glycemia. The glucose management indicator (GMI) was calculated as $3.31+0.02392 *$ mean CGM glucose $(\mathrm{mg} / \mathrm{dL})$ (23). In a sensitivity analysis, we restricted analyses to the mean CGM blood glucose calculated only from the 6-day CGM period that immediately preceded the biomarker blood draw. 


\section{Covariate Data}

Demographics and medical history were ascertained through self-report, while trained research coordinators inventoried medications with assistance from electronic health records. Serum creatinine, hemoglobin, albumin, iron, and transferrin were measured using a DxC automated chemistry analyzer (Beckman Coulter, Brea, CA). Serum creatinine was measured using a modified Jaffe reaction, with results traceable to isotope dilution mass spectrometry. eGFR was calculated using the creatinine-only Chronic Kidney Disease Epidemiology Collaboration equation (24). Urine albumin and urine creatinine were collected from spot urines at the end of the second CGM period and measured using a turbidimetric method on a DxC automated chemistry analyzer.

\section{Statistical Analysis}

We used scatterplots and Pearson correlation coefficients to investigate the repeatability of glycemia markers between CGM periods as well as the relationship between change in the biomarker and change in the CGM mean glucose. Inferential comparisons of Pearson correlation coefficients used Fisher r-to-z transformation (25). We used linear regression of each biomarker on CGM mean glucose with robust Huber-White SEs (26) to quantify the variability and accuracy of each biomarker. From this regression, we calculated the proportion (denoted $\mathrm{p}_{10}$, etc.) of observed biomarkers that fell within $10 \%$ (and $20 \%$ and $30 \%$ ) of the value predicted by the regression. We also regressed the squared residuals on eGFR to evaluate whether the variability of the biomarker might vary by eGFR. Finally, we examined the covariate determinants of bias, defined as the difference in the mean biomarker comparing those with different values of the covariate but the same mean CGM glucose. To do this, we performed linear regression of the log-transformed glycemic marker on the potential determinant of bias adjusted for the CGM mean glucose. All primary regression analyses excluded one participant with a highly unusual $\mathrm{HbA}_{1 \mathrm{c}}$-to-mean $\mathrm{CGM}$ glucose relationship.

For the primary analysis, we preferentially used the biomarker measurements taken from the end of the second CGM period; when these were unavailable ( $n=11$ participants), we instead used measurements collected at the end of the first CGM period. In a sensitivity analysis, we repeated analyses in the subset of participants ( $n=92$ ) with complete glycemia marker measurements from the end of the second CGM period. In another sensitivity analysis, we restricted analysis to use only the CGM period that immediately preceded the biomarker collection. Finally, we performed a sensitivity analysis of the covariate determinants of bias of albumin-corrected fructosamine, defined as fructosamine divided by the albumin result from the glycated albumin measurement ( $\mu$ mol fructosamine/ umol albumin).

All analyses were conducted using the $R$ 3.6.0 software environment ( $R$ Foundation for Statistical Computing, Vienna, Austria). A two-tailed $P<0.05$ was taken as evidence of statistical significance in all analyses.

\section{RESULTS}

\section{Participant Characteristics}

Of the 104 participants included in this study, 80 (77\%) had eGFR $<60 \mathrm{~mL} / \mathrm{min} /$ $1.73 \mathrm{~m}^{2}, 67(64 \%)$ were male, and $80(77 \%)$ were White (Table 1$)$. The mean age was 68 (SD 10) years, and BMI was 33 (SD 6) kg/m². Participants had a mean duration of diabetes of 19 (SD 10) years and $\mathrm{HbA}_{1 \mathrm{c}}$ of $7.7 \%$ (SD $1.3 \%$ ) or 61 (SD 14.8) $\mathrm{mmol} / \mathrm{mol}$. During the CGM periods, the mean of each participant's mean CGM blood glucose was 168 (SD 38) mg/dL.

\section{Repeatability of Glycemia Markers}

Ninety-two (88\%) study participants had complete biomarker measurements at the end of the first and second CGM periods. Biomarker values at the end of the first period were strongly correlated with the values at the end of the second period $\left(\mathrm{HbA}_{1 \mathrm{c}}, r=0.95\right.$; glycated albumin, $r=0.93$; fructosamine, $r=0.92$ ) (Table 2 and Supplementary Figs. 1 and 2). In contrast, there was markedly less concordance in the CGM mean blood glucose between the two periods ( $r=$ 0.77). The change in CGM mean glucose between the two periods was more strongly correlated with the change in glycated albumin $(r=0.67)$ than with the change in fructosamine $(r=0.48)$ or $\mathrm{HbA}_{1 \mathrm{c}}(r=0.26)$. Within-person correlation of all biomarkers and the correlation of change in each biomarker with the change in CGM mean glucose tended to be stronger among participants with eGFR $<60 \mathrm{~mL} / \mathrm{min} / 1.73 \mathrm{~m}^{2}$ than among those with eGFR $\geq 60 \mathrm{~mL} /$ $\min / 1.73 \mathrm{~m}^{2}$.

Variability, Accuracy, and Bias of $\mathrm{HbA}_{1 \mathrm{c}}$ $\mathrm{HbA}_{1 \mathrm{c}}$ showed strong correlation with CGM mean blood glucose among all participants $(r=0.78)$ and in those with eGFR $<60 \mathrm{~mL} / \mathrm{min} / 1.73 \mathrm{~m}^{2}(r=$ 0.78) (23) (Table 3 and Fig. 1). Observed values of $\mathrm{HbA}_{1 \mathrm{c}}$ fell within $10 \%$ of the value predicted by the mean CGM glucose $77 \%$ of the time, and $\mathrm{HbA}_{1 \mathrm{c}}$ was significantly more variable as a marker of CGM mean glucose for participants with lower eGFR ( $P=0.02$ ) (Fig. 2). We saw little bias in $\mathrm{HbA}_{1 \mathrm{c}}$ for the mean CGM glucose by measured covariates, with the exception of albuminuria (urine albuminto-creatinine ratio $[\mathrm{UACR}]>1,000 \mathrm{mg} / \mathrm{g}$ ) (Table 4 and Supplementary Fig. 3). There was no significant bias observed in $\mathrm{HbA}_{1 \mathrm{c}}$ by level of hemoglobin, serum iron, or transferrin saturation.

\section{Variability, Accuracy, and Bias of} Alternative Markers of Glycemia Overall, there was a strong correlation among all markers of glycemia, particularly between glycated albumin and fructosamine; no marker of glycemia correlated with glucose variability as measured by $\mathrm{CV} \%$ of glucose readings (Supplementary Table 2). We observed similar Pearson correlations of the three biomarkers of glycemia with CGM mean blood glucose among all participants $\left(\mathrm{HbA}_{1 \mathrm{c}}, r=0.78\right.$; glycated albumin, $r=0.77$; fructosamine, $r=0.71$ ) and in those with eGFR $<60 \mathrm{~mL} / \mathrm{min} / 1.73 \mathrm{~m}^{2}$ $\left(\mathrm{HbA}_{1 \mathrm{c}}, r=0.78\right.$; glycated albumin, $r=$ 0.78; fructosamine, $r=0.71$ ) (Table 3). Observed values fell within $10 \%$ of the predicted value more often for $\mathrm{HbA}_{1 c}$ $\left(p_{10}=77 \%\right)$ than for either glycated albumin $\left(\mathrm{p}_{10}=56 \%\right)$ or fructosamine $\left(p_{10}=61 \%\right)$ both in participants overall and in those with and without eGFR $<60$ $\mathrm{mL} / \mathrm{min} / 1.73 \mathrm{~m}^{2}$. Like $\mathrm{HbA}_{1 \mathrm{c}}$, both glycated albumin and fructosamine were significantly more variable as a marker of CGM mean glucose for participants with lower eGFR (glycated albumin, $P=0.03$; fructosamine, $P=0.01$ ) (Fig. 2).

For participants with the same CGM mean blood glucose, statistically significant lower glycated albumin and 
Table 1-Baseline characteristics of analytic population, overall and by eGFR

\begin{tabular}{|c|c|c|c|}
\hline & Overall $(N=104)$ & $\begin{array}{c}\text { eGFR }<60 \mathrm{~mL} / \mathrm{min} / 1.73 \mathrm{~m}^{2} \\
(n=80)\end{array}$ & $\begin{array}{c}\text { eGFR } \geq 60 \mathrm{~mL} / \mathrm{min} / 1.73 \mathrm{~m}^{2} \\
(n=24)\end{array}$ \\
\hline Age (years), mean (SD) & $67.5(9.9)$ & $68.4(9.6)$ & $64.3(10.3)$ \\
\hline Male, $n(\%)$ & $67(64)$ & $52(65)$ & $15(62)$ \\
\hline \multicolumn{4}{|l|}{ Race, $n(\%)$} \\
\hline White & $80(77)$ & $60(75)$ & $20(83)$ \\
\hline Black & $13(12)$ & $11(14)$ & $2(8)$ \\
\hline Other & $11(11)$ & $9(11)$ & $2(8)$ \\
\hline Hispanic ethnicity, $n$ (\%) & $11(11)$ & $8(10)$ & $3(12)$ \\
\hline History of MI, $n(\%)$ & $14(13)$ & $13(16)$ & $1(4)$ \\
\hline History of CHF, $n(\%)$ & $19(18)$ & $18(22)$ & $1(4)$ \\
\hline History of stroke, $n(\%)$ & $12(12)$ & 11 (14) & $1(4)$ \\
\hline Duration of diabetes (years), mean (SD) & $19.1(10.0)$ & $20.0(10.4)$ & $15.9(8.4)$ \\
\hline $\mathrm{BMI}\left(\mathrm{kg} / \mathrm{m}^{2}\right)$, mean (SD) & $33.4(5.7)$ & $33.6(5.6)$ & $32.4(6.2)$ \\
\hline Systolic blood pressure $(\mathrm{mmHg})$, mean (SD) & $133(21)$ & $132(21)$ & $136(17)$ \\
\hline Diastolic blood pressure (mmHg), mean (SD) & $73(13)$ & $72(13)$ & $78(12)$ \\
\hline eGFR (CKD-EPI) $\left(\mathrm{mL} / \mathrm{min} / 1.73 \mathrm{~m}^{2}\right)$, mean (SD) & $48(23)$ & $38(14)$ & $83(11)$ \\
\hline$<30 \mathrm{~mL} / \mathrm{min} / 1.73 \mathrm{~m}^{2}, n(\%)$ & $22(21)$ & $22(28)$ & $0(0)$ \\
\hline uACR $(\mathrm{mg} / \mathrm{g})$, median (IQR) & $88(16-604)$ & $142(31-675)$ & $15(8-37)$ \\
\hline$>1,000 \mathrm{mg} / \mathrm{g}, n(\%)$ & $16(15)$ & $14(18)$ & $2(8)$ \\
\hline Hemoglobin (g/dL), mean (SD) & $12.4(1.8)$ & $12.2(1.6)$ & $13.1(2.0)$ \\
\hline Anemia, $n(\%)$ & $38(37)$ & $30(38)$ & $8(33)$ \\
\hline Serum albumin $(\mathrm{g} / \mathrm{dL})$, mean (SD) & $3.7(0.4)$ & $3.7(0.4)$ & $3.7(0.4)$ \\
\hline$<3 \mathrm{~g} / \mathrm{dL}, n(\%)$ & $6(6)$ & $4(5)$ & $2(8)$ \\
\hline Serum iron $(\mu \mathrm{g} / \mathrm{dL})$, mean $(S D)$ & $66(23)$ & $65(23)$ & $68(23)$ \\
\hline Transferrin saturation (\%), mean (SD) & $27(11)$ & $27(11)$ & $27(11)$ \\
\hline Mean CGM glucose (mg/dL), mean (SD) & $168(38)$ & $170(40)$ & $158(30)$ \\
\hline GMI (\%), mean (SD) & $7.3(0.9)$ & $7.4(1.0)$ & $7.1(0.7)$ \\
\hline $\mathrm{HbA}_{1 \mathrm{c}}(\%)$, mean (SD) & $7.7(1.3)$ & $7.8(1.4)$ & $7.7(1.3)$ \\
\hline $\mathrm{HbA}_{1 \mathrm{c}}(\mathrm{mmol} / \mathrm{mol})$, mean (SD) & $61(14.8)$ & $61(15.1)$ & $60(13.8)$ \\
\hline Glycated albumin (\%), mean (SD) & $18.7(4.8)$ & $19.1(5.0)$ & $17.6(3.6)$ \\
\hline Fructosamine ( $\mu \mathrm{mol} / \mathrm{L})$, mean (SD) & $304(59)$ & $310(61)$ & $285(49)$ \\
\hline
\end{tabular}

$\mathrm{GMI}$ is defined as $3.31+0.02392 *$ mean CGM glucose $(\mathrm{mg} / \mathrm{dL})$ (23). Anemia is defined as hemoglobin $<11.5 \mathrm{~g} / \mathrm{dL}$ for females and $<13 \mathrm{~g} / \mathrm{dL}$ for males $\mathrm{CHF}$, congestive heart failure; IQR, interquartile range; $\mathrm{MI}$, myocardial infarction.

fructosamine were observed in those of younger age; those with a higher BMI, lower serum iron, and lower transferrin saturation; and those with albuminuria (uACR $>1,000 \mathrm{mg} / \mathrm{g}$ ) (Table 4 and Supplementary Figs. 4 and 5). Estimates of bias in glycated albumin and fructosamine tended to be in the same direction and of similar magnitude (Supplementary Fig. 6). Fructosamine, among participants with the same CGM mean blood glucose, was also higher in those with higher serum albumin. Notably, there appeared to be little bias across the range of eGFR (Fig. 2).

These patterns of accuracy and bias persisted when restricting to the most recent CGM (Supplementary Tables 8 and 9) and to only those participants with biomarkers measured at the end of the two CGM periods (Supplementary Tables 10 and 11). Results were also largely similar when excluding three influential participants (Supplementary Table 14). A sensitivity analysis of albumin-corrected fructosamine showed overestimation with higher age and lower eGFR and underestimation with higher BMI, hemoglobin, and serum albumin (Supplementary Table 7). We observed no statistically significant bias by sex or race/ethnicity for any marker of glycemia.

\section{CONCLUSIONS}

Among adults with type 2 diabetes and a range of eGFR who were not treated with dialysis or ESAs, neither glycated albumin nor fructosamine was a better surrogate of mean CGM glucose than $\mathrm{HbA}_{1 \mathrm{c}}$. The difference between measured $\mathrm{HbA}_{1 \mathrm{c}}$ and predicted $\mathrm{HbA}_{1 \mathrm{c}}$ on the basis of mean CGM glucose tended to be less variable than the corresponding differences between observed and predicted values for glycated albumin and fructosamine, and both glycated albumin and fructosamine had more sources of bias than $\mathrm{HbA}_{1 \mathrm{c}}$. Results were consistent among participants with normal and reduced eGFR, although relatively few participants had eGFR $<30 \mathrm{~mL} / \mathrm{min} / 1.73 \mathrm{~m}^{2}$. Notably, changes in neither $\mathrm{HbA}_{1 \mathrm{c}}$, glycated albumin, nor fructosamine captured the week-to-week or shorter-term variability of the CGM-derived measurement. Altogether, these findings support the use of $\mathrm{HbA}_{1 \mathrm{c}}$ over glycated albumin or fructosamine for monitoring of long-term glycemia in patients with type 2 diabetes and 
Table 2-Within-person repeatability of glycemia markers and mean CGM glucose over $\sim 3$ weeks, overall and by eGFR

\begin{tabular}{|c|c|c|c|c|c|c|}
\hline & \multicolumn{2}{|r|}{ Overall } & \multicolumn{2}{|c|}{ eGFR $<60 \mathrm{~mL} / \mathrm{min} / 1.73 \mathrm{~m}^{2}$} & \multicolumn{2}{|c|}{ eGFR $\geq 60 \mathrm{~mL} / \mathrm{min} / 1.73 \mathrm{~m}^{2}$} \\
\hline & $\begin{array}{c}\text { Within-person } \\
\text { correlation }\end{array}$ & $\begin{array}{l}\text { Correlation of change in } \\
\text { biomarker with change in } \\
\text { CGM mean glucose }\end{array}$ & $\begin{array}{c}\text { Within-person } \\
\text { correlation }\end{array}$ & $\begin{array}{c}\text { Correlation of change in } \\
\text { biomarker with change in } \\
\text { CGM mean glucose }\end{array}$ & $\begin{array}{c}\text { Within-person } \\
\text { correlation }\end{array}$ & $\begin{array}{c}\text { Correlation of change in } \\
\text { biomarker with change in } \\
\text { CGM mean glucose }\end{array}$ \\
\hline $\mathrm{HbA}_{1 \mathrm{c}}$ & 0.95 & 0.26 & 0.96 & 0.31 & 0.88 & 0.05 \\
\hline $\begin{array}{l}\text { Glycated } \\
\text { albumin }\end{array}$ & 0.93 & 0.67 & 0.94 & 0.73 & 0.94 & 0.38 \\
\hline Fructosamine & 0.92 & 0.48 & 0.93 & 0.55 & 0.91 & 0.25 \\
\hline $\begin{array}{l}\text { CGM mean } \\
\text { glucose }\end{array}$ & 0.77 & - & 0.76 & - & 0.78 & - \\
\hline
\end{tabular}

Analyses exclude one participant with an implausible $\mathrm{HbA}_{1 \mathrm{c}}$-to-mean $\mathrm{CGM}$ glucose relationship.

eGFR $<60 \mathrm{~mL} / \mathrm{min} / 1.73 \mathrm{~m}^{2}$ not treated with dialysis.

In this study, $\mathrm{HbA}_{1 \mathrm{c}}$, glycated albumin, and fructosamine all had high withinperson correlation (0.92-0.95) when measured $\sim 3$ weeks apart. The stability of these markers indicates low withinperson variability over this time frame, which in turn provides reassurance for epidemiologic studies that use these measures. Over $\sim 3$ weeks, CGM mean glucose was observed to vary within an individual more than the biomarkers did, and change in none of the biomarkers fully reflected the change in CGM mean glucose. Changes in CGM mean glucose could reflect variability as a result of lifestyle, medication use, or in some cases, physician intervention. While $\mathrm{HbA}_{1 \mathrm{c}}$ would not be expected to vary greatly over this time period because of the longer life span of RBCs $(\sim 120$ days), glycated albumin and fructosamine reflect a shorter-term (2-3 week) average glycemic burden and might be expected to have lower within-person correlation. However, changes in glycated albumin reflected changes in mean glucose more closely than changes in fructosamine or $\mathrm{HbA}_{1 \mathrm{c}}$ did. While glycated albumin and fructosamine are conceptually similar, fructosamine reflects glycation of other proteins beyond albumin, such as globulins, which have both a longer half-life than albumin and a wide metabolic heterogeneity (27). We speculate that the contributions of other glycated proteins may explain why changes in fructosamine corresponded less closely than glycated albumin to changes in mean glucose.

None of the biomarkers were strongly correlated with CV\% or time below range, clinically important measures of glucose variability and hypoglycemia. While the focus of this report was the evaluation of biomarkers as a tool to monitor longterm trends in glycemia, it should be noted that no biomarker captured clinically important minute-to-minute variability. In addition to quantifying mean glucose levels, CGM can be used to detect and mitigate moment-to-moment alterations in blood glucose, allowing for improved glycemic management, particularly when results are available real time. As a result, direct measurement of blood glucose (e.g., with CGM) is necessary if capturing short-term variability and episodes of hypoglycemia are important.

Previous studies have raised questions about whether $\mathrm{HbA}_{1 \mathrm{c}}$ is an appropriate surrogate of glycemia among patients with reduced GFR. For example, a 2012 study (2) found a similar correlation of $\mathrm{HbA}_{1 \mathrm{c}}$ and mean glucose as our study in 25 subjects with diabetes and no kidney disease $(r=0.66)$ but a much lower correlation $(r=0.38)$ in 25 age- and sexmatched subjects with diabetes and eGFR $<30 \mathrm{~mL} / \mathrm{min} / 1.73 \mathrm{~m}^{2}$. In that study, $\mathrm{HbA}_{1 \mathrm{c}}$ significantly underestimated glycemia in patients with diabetes and eGFR $<30 \mathrm{~mL} / \mathrm{min} / 1.73 \mathrm{~m}^{2}$; a 2010 study of 30 patients with diabetes and eGFR $<60 \mathrm{~mL} / \mathrm{min} / 1.73 \mathrm{~m}^{2}$ reached similar conclusions (19). In contrast, our

Table 3-Measures of correlation, variability, and accuracy of glycemia markers for mean CGM glucose, overall and by eGFR strata

\begin{tabular}{|c|c|c|c|c|c|c|c|c|c|}
\hline \multirow[b]{2}{*}{ Metric } & \multicolumn{3}{|c|}{ Overall } & \multicolumn{3}{|c|}{ eGFR $<60 \mathrm{~mL} / \mathrm{min} / 1.73 \mathrm{~m}^{2}$} & \multicolumn{3}{|c|}{$\mathrm{eGFR} \geq 60 \mathrm{~mL} / \mathrm{min} / 1.73 \mathrm{~m}^{2}$} \\
\hline & $\mathrm{HbA}_{1 \mathrm{c}}$ & $\begin{array}{l}\text { Glycated } \\
\text { albumin }\end{array}$ & Fructosamine & $\mathrm{HbA}_{1 \mathrm{c}}$ & $\begin{array}{l}\text { Glycated } \\
\text { albumin }\end{array}$ & Fructosamine & $\mathrm{HbA}_{1 \mathrm{c}}$ & $\begin{array}{l}\text { Glycated } \\
\text { albumin }\end{array}$ & Fructosamine \\
\hline Pearson $r$ & 0.78 & 0.77 & 0.71 & 0.78 & 0.78 & 0.71 & 0.76 & 0.72 & 0.63 \\
\hline Spearman $r$ & 0.74 & 0.69 & 0.63 & 0.75 & 0.66 & 0.63 & 0.65 & 0.79 & 0.68 \\
\hline $\begin{array}{l}\text { Absolute } \\
\text { residuals, } \\
\text { median } \\
\text { (IQR) }\end{array}$ & $\begin{array}{l}-0.0(-0.4 \\
\text { to } 0.5)\end{array}$ & $\begin{array}{l}-0.1(-1.7 \\
\text { to } 1.4)\end{array}$ & $\begin{array}{c}-4.7(-19.4 \\
\text { to } 21.9)\end{array}$ & $\begin{array}{l}0.0(-0.4 \\
\text { to } 0.5)\end{array}$ & $\begin{array}{l}0.0(-1.8 \\
\text { to } 1.3)\end{array}$ & $\begin{array}{c}-7.1(-20.7 \\
\text { to } 19.2)\end{array}$ & $\begin{array}{c}-0.3(-0.4 \\
\text { to } 0.4)\end{array}$ & $\begin{array}{c}-0.2(-1.5 \\
\text { to } 1.0)\end{array}$ & $\begin{array}{c}8.7(-32.6 \\
\text { to } 23.2)\end{array}$ \\
\hline $\mathrm{p}_{10}(\%)$ & 77 & 56 & 61 & 75 & 55 & 64 & 78 & 52 & 43 \\
\hline$p_{20}(\%)$ & 92 & 81 & 83 & 90 & 79 & 84 & 100 & 91 & 83 \\
\hline$p_{30}(\%)$ & 99 & 94 & 97 & 99 & 92 & 95 & 100 & 100 & 100 \\
\hline
\end{tabular}

Correlations are the correlation of the biomarker with CGM mean glucose. Residuals come from a linear regression of the biomarker on the mean CGM glucose; units for residuals are percent for $\mathrm{HbA}_{1 \mathrm{c}}$ and glycated albumin and micromoles per liter for fructosamine. $\mathrm{p}_{10}, \mathrm{p}_{20}$, and $\mathrm{p}_{30}$ are the proportion of observed biomarkers that fall within $10 \%, 20 \%$, and $30 \%$ of the predicted value of the biomarker from the linear regression, respectively. Analyses exclude one participant with an implausible $\mathrm{HbA}_{1 \mathrm{c}}$-to-mean $\mathrm{CGM}$ glucose relationship. IQR, interquartile range. 

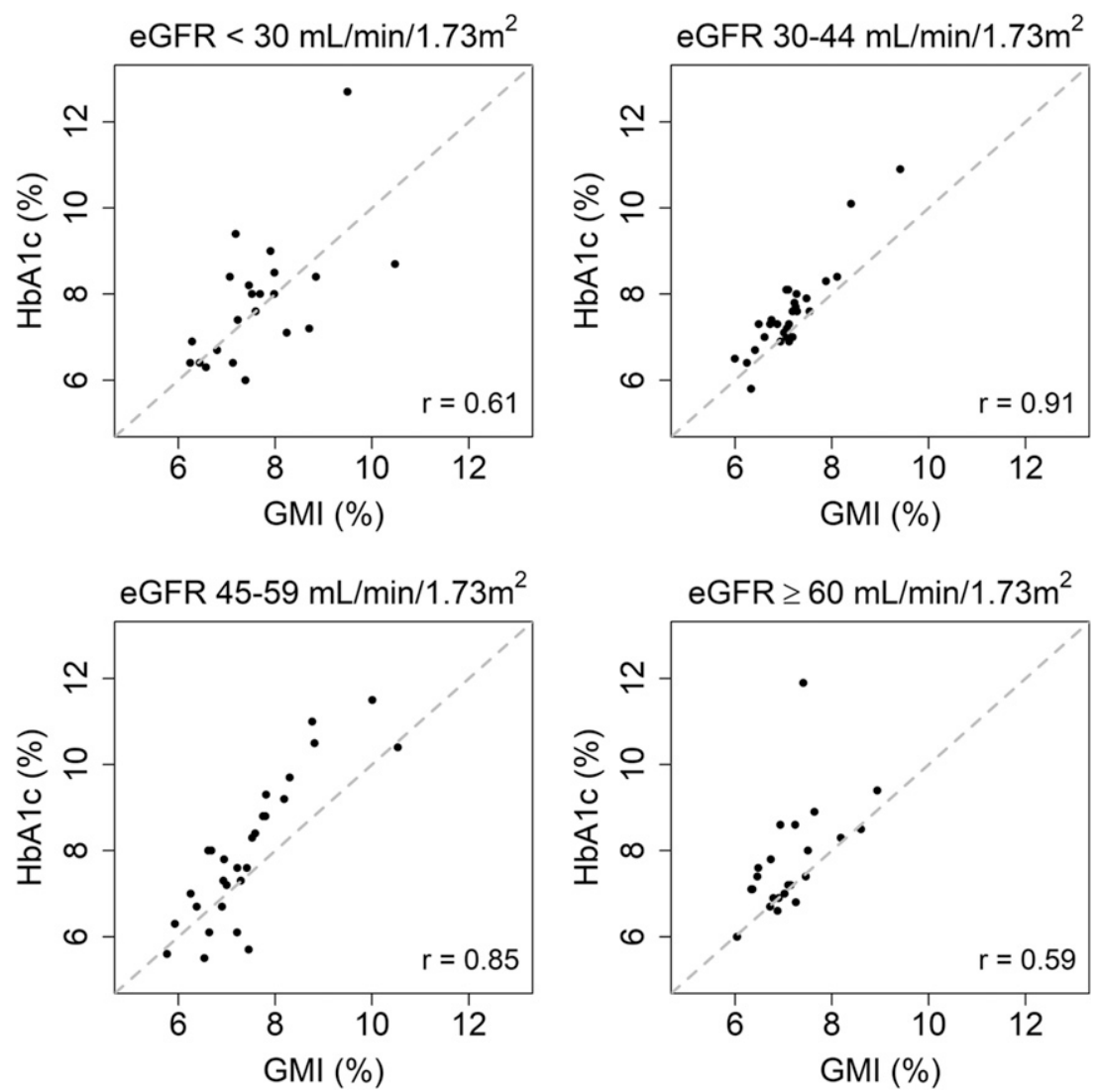

Figure $1-\mathrm{HbA}_{1 \mathrm{c}}$ and GMI by CKD stage. GMI is defined as $3.31+0.02392 *$ mean CGM glucose $(\mathrm{mg} / \mathrm{dL})$. Dashed lines indicate the line of identity.

study showed that $\mathrm{HbA}_{1 \mathrm{c}}$ performed reasonably well among participants with mild to moderate CKD. We found that $\mathrm{HbA}_{1 \mathrm{c}}$ had good correlation $(r=$ 0.78) with CGM mean glucose and low variability $\left(\mathrm{p}_{10}=77 \%\right)$; these values among participants with eGFR $<60 \mathrm{~mL} /$ $\min / 1.73 \mathrm{~m}^{2}$ were similar to those with normal eGFR. Notably, we observed in this study no bias by eGFR, even among those with eGFR $<30 \mathrm{~mL} / \mathrm{min} / 1.73 \mathrm{~m}^{2}$, although there were relatively few $(n=22)$ participants in this range, and participants in our study were not treated with ESAs. However, we found evidence that the difference between observed $\mathrm{HbA}_{1 \mathrm{c}}$ and the expected value on the basis of mean CGM glucose was significantly more variable for those with lower eGFR. In another study of moderate to severe CKD, Lo et al. (28) found a correlation of mean CGM glucose with $\mathrm{HbA}_{1 \mathrm{c}}(r=0.79)$ similar to that in our study among patients with eGFR 30$59 \mathrm{~mL} / \mathrm{min} / 1.73 \mathrm{~m}^{2}$, which did not differ significantly from an indirect comparator group from the A1C-Derived Average Glucose (ADAG) study $(r=0.74)$. In that study, the correlation was substantially lower
( $r=0.34$ ) among participants with eGFR $<30 \mathrm{~mL} / \mathrm{min} / 1.73 \mathrm{~m}^{2}$, although it should be noted that nearly all of these used ESAs. Future studies should focus on people with $<30 \mathrm{~mL} / \mathrm{min} /$ $1.73 \mathrm{~m}^{2}$.

In contrast to prior research, we found few non-GFR sources of bias in $\mathrm{HbA}_{1 \mathrm{c}}$. Previous studies have noted concerns about poor estimation of $\mathrm{HbA}_{1 \mathrm{c}}$ in patients with CKD because the production and life span of RBCs are reduced (29), while medications such as ESAs used to treat the condition can change the fraction of young red cells (30). We found no bias in $\mathrm{HbA}_{1 \mathrm{c}}$ by level of hemoglobin, serum iron, or transferrin saturation; one possible explanation for the differing results is that the level of CKD studied here was too mild to affect RBC turnover. These results are generalizable only to patients not treated with ESAs, for whom results may differ. Among patients with eGFR $<60 \mathrm{~mL} / \mathrm{min} / 1.73 \mathrm{~m}^{2}$, many of whom were treated with ESAs, Lo et al. (28) found significant bias in $\mathrm{HbA}_{1 \mathrm{c}}$ by anemia status and by ESA treatment. However, while still common among patients treated with dialysis, ESA treatment has become less common among those not on dialysis since randomized trials have shown no cardiovascular benefit and potential harm with ESAs (31-34). Relatively few participants in our study were anemic, so further research on biomarker performance as a surrogate of glycemia is needed in this subgroup.

Unexpectedly, we did observe some evidence of bias in $\mathrm{HbA}_{1 \mathrm{c}}$ among participants with albuminuria. In exploratory analyses (data not shown), the association was no longer significant when additionally adjusted for eGFR. Together with the observation that participants with albuminuria tended to have lower eGFR, we speculate that the observed result may partially reflect differences in $\mathrm{HbA}_{1 \mathrm{c}}$ across levels of eGFR. This surprising result should be evaluated in future studies to be confirmed.

Although they have been proposed as superior alternatives to $\mathrm{HbA}_{1 \mathrm{c}}$, in this study, glycated albumin and fructosamine performed no better than $\mathrm{HbA}_{1 \mathrm{c}}$ with respect to CGM mean glucose either overall or in participants with CKD. In particular, several participant characteristics significantly biased the observed serum concentrations of glycated albumin and fructosamine compared with those predicted by mean CGM glucose. Glycated albumin and fructosamine were lower than expected for participants with albuminuria, lower serum iron concentration, lower transferrin saturation, younger age, and higher BMI. We speculate that people with these characteristics may have higher albumin turnover, allowing less time for albumin glycation. Albumin turnover is known to be increased with heavy urinary albumin loss (35). Absent albuminuria, catabolism is the most important mechanism of albumin clearance, but clinical determinants of catabolism are not well described (36). Higher BMI has been previously associated with lower distributions of glycated albumin and fructosamine concentration (37), and our data suggest this is not attributable to lower glycemic exposure.

The differences between the observed and predicted biomarkers were more variable overall for glycated albumin and fructosamine than for $\mathrm{HbA}_{1 \mathrm{c}}$ and for all markers, this difference showed significantly greater variability in participants 

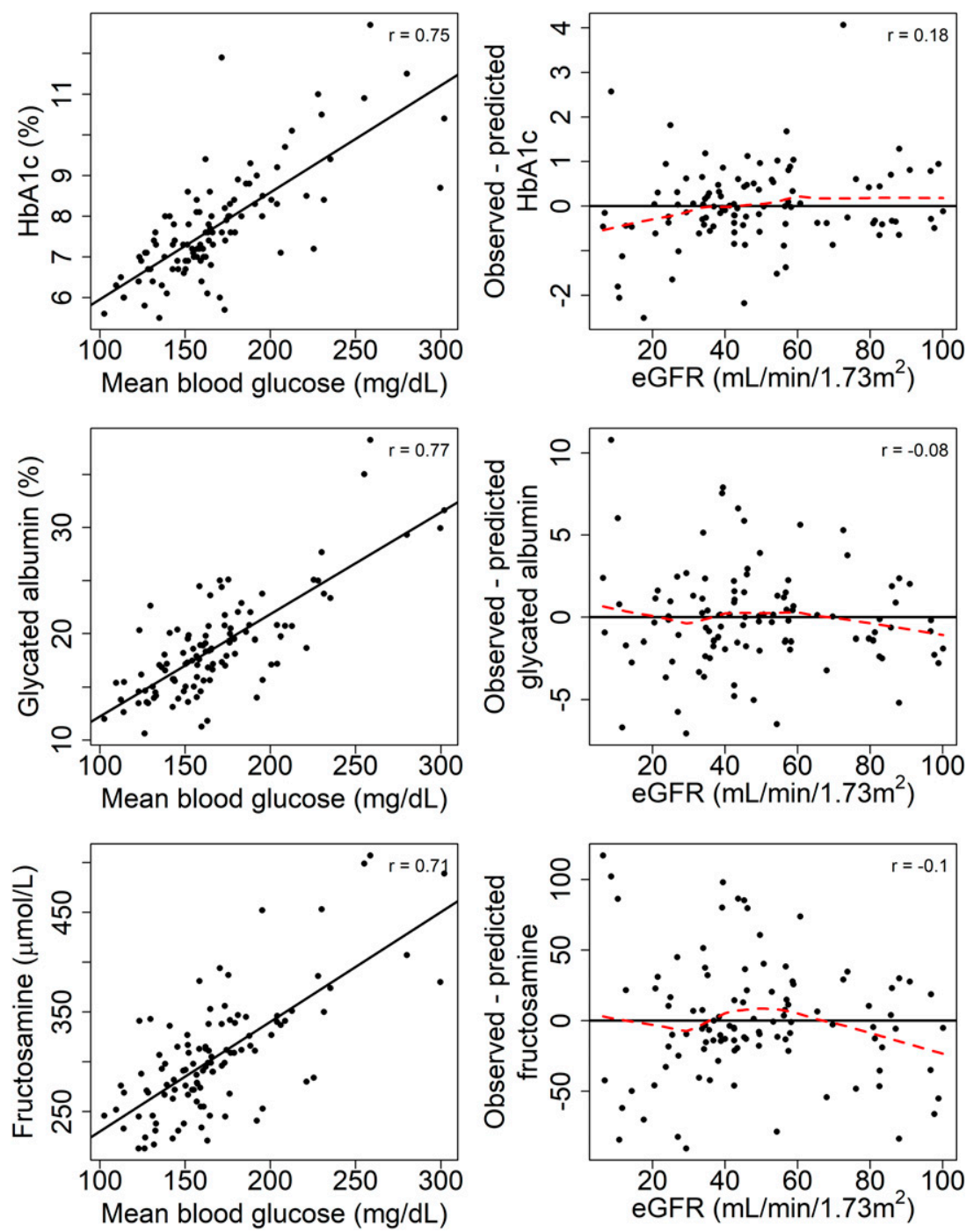

Figure 2-Glycemic markers and mean CGM blood glucose and difference in observed and predicted biomarker and eGFR values. Predicted biomarker values were derived from the linear regression of the biomarker on mean CGM glucose.

with lower GFR than in those with normal GFR. A 2018 study by Jung et al. (38) of cross-sectional associations of these markers of glycemia across categories of eGFR in 1,665 Atherosclerosis Risk in Communities Study participants with diagnosed diabetes age $>65$ years found similar correlations of glycated albumin, fructosamine, and $\mathrm{HbA}_{1 \mathrm{c}}$ with fasting glucose in those with eGFR $<60 \mathrm{~mL} /$ $\min / 1.73 \mathrm{~m}^{2}$, with worse correlation among those with the lowest eGFR. However, the study compared these markers with a single fasting blood glucose, not mean CGM glucose. Among a Japanese cohort of 41 patients treated with dialysis and 56 patients without kidney disease, Hayashi et al. (39) found that unlike $\mathrm{HbA}_{1 \mathrm{c}}$, glycated albumin estimated mean CGM glucose correctly on average but was more variable than $\mathrm{HbA}_{1 \mathrm{c}}$. Further studies using CGM are needed to fully understand the utility of these biomarkers in the dialysis population.

Our study had several notable strengths. A state-of-the-art CGM system was able to comprehensively characterize glycemia over an average of 11 days per participant. The sample size was the largest to date for a study of glycemic biomarkers compared with CGM. We studied participants across a wide range of eGFR $\left(6-100 \mathrm{~mL} / \mathrm{min} / 1.73 \mathrm{~m}^{2}\right)$, including 80 participants with eGFR $<60$ $\mathrm{mL} / \mathrm{min} / 1.73 \mathrm{~m}^{2}$ who represent $14 \%$ of all U.S. adults with diabetes (40). The biomarkers that we evaluated were all measured in a specialized NGSP diabetes testing laboratory. However, we do recognize some limitations as well. As a cross-sectional study, biomarkers were not linked with either clinical or patient-reported outcomes. The sample size, while relatively large, did not permit definitive evaluation of biomarkers within pertinent subgroups, such as participants with eGFR $<30 \mathrm{~mL} / \mathrm{min} /$ $1.73 \mathrm{~m}^{2}$, participants with anemia, or race/ ethnicity. There may be combinations of factors, such as those related to eGFR, $\mathrm{UACR}$, anemia, and hypoalbuminemia, for which $\mathrm{HbA}_{1 \mathrm{c}}$ performs more poorly; we were unable to investigate these subgroups further because of limited sample size. Not all participants had $>10$ days of analyzable CGM data recommended by consensus guidelines (41).

In conclusion, our results suggest that $\mathrm{HbA}_{1 \mathrm{c}}$ is no more variable and less biased than glycated albumin and fructosamine in patients with type 2 diabetes and eGFR $<60 \mathrm{~mL} / \mathrm{min} / 1.73 \mathrm{~m}^{2}$ not treated with dialysis, supporting guideline recommendations to measure $\mathrm{HbA}_{1 \mathrm{c}}$ to monitor long-term trends in glycemia in this population. However, direct measurements of blood glucose, such as those obtained using CGM, are necessary to capture week-to-week and shorter-term variability, which these markers of glycemia do not reflect.

Funding. The CANDY study was primarily supported by American Diabetes Association grant \#4-15-CKD-20. Additional funding came from National Institute of Diabetes and Digestive and Kidney Diseases grants R01-DK-088762, R01-DK-087726, and T32-DK-007247; a Puget Sound Veterans Affairs Health Care System grant; and a Northwest Kidney Centers unrestricted grant. CGM equipment and supplies were donated by Medtronic, and self-monitored blood glucose equipment and supplies were donated by Abbott Laboratories.

Study sponsors had no role in designing the study, collecting study data, or analyzing or presenting study results.

Duality of Interest. D.L.T. reports support from Sanofi and Medtronic outside the submitted work. I.B.H. reports grants from Medtronic Diabetes and Insulet, personal fees from Abbott Diabetes Care, personal fees from Roche, and personal fees from Bigfoot Biomedical outside the submitted work. I.H.d.B. reports nonfinancial support from Medtronic and nonfinancial support from Abbott Laboratories during the conduct of the study, personal fees from Boehringer Ingelheim, and personal fees from Ironwood outside the submitted work. No other potential conflicts of interest relevant to this article were reported. Author Contributions. L.R.Z. analyzed and interpreted data and wrote the manuscript. Z.O.B., I.A., and R.R.L. collected, analyzed, and interpreted data and critically reviewed the 
Table 4-Covariate determinants of bias of glycemic markers

\begin{tabular}{|c|c|c|c|c|c|c|}
\hline & \multicolumn{2}{|l|}{$\mathrm{HbA}_{1 \mathrm{c}}$} & \multicolumn{2}{|c|}{ Glycated albumin } & \multicolumn{2}{|c|}{ Fructosamine } \\
\hline & $\%$ difference $(95 \% \mathrm{Cl})$ & $P$ value & $\%$ difference $(95 \% \mathrm{Cl})$ & $P$ value & $\%$ difference $(95 \% \mathrm{Cl})$ & $P$ value \\
\hline Age (per 10 year increment) & $-1.6(-3.4,0.2)$ & 0.08 & $5.6(2.1,9.3)$ & 0.002 & $4.9(2.0,8.0)$ & 0.0009 \\
\hline Male sex & $-2.3(-6.1,1.6)$ & 0.24 & $1.2(-5.2,8.0)$ & 0.72 & $4.8(-0.5,10.4)$ & 0.08 \\
\hline \multicolumn{7}{|l|}{ Race/ethnicity } \\
\hline Black & $-4.7(-13.4,4.8)$ & 0.32 & $-3.6(-15.6,10.1)$ & 0.59 & $-2.0(-11.3,8.2)$ & 0.69 \\
\hline Other & $-2.9(-9.1,3.7)$ & 0.38 & $2.1(-5.4,10.2)$ & 0.6 & $-0.5(-8.6,8.4)$ & 0.91 \\
\hline BMI (per $5 \mathrm{~kg} / \mathrm{m}^{2}$ increment) & $-0.8(-2.5,1.0)$ & 0.38 & $-4.0(-6.6,-1.3)$ & 0.004 & $-4.0(-6.0,-1.9)$ & 0.0002 \\
\hline $\begin{array}{l}\text { eGFR (per } 15 \mathrm{~mL} / \mathrm{min} / 1.73 \mathrm{~m}^{2} \\
\text { decrement) }\end{array}$ & $-1.1(-2.3,0.2)$ & 0.09 & $0.6(-1.2,2.5)$ & 0.5 & $0.8(-1.1,2.7)$ & 0.41 \\
\hline eGFR $<30 \mathrm{~mL} / \mathrm{min} / 1.73 \mathrm{~m}^{2}$ & $-4.0(-9.3,1.6)$ & 0.15 & $-2.4(-10.3,6.2)$ & 0.57 & $-3.6(-10.7,4.1)$ & 0.35 \\
\hline uACR (per doubling) & $-0.2(-0.9,0.4)$ & 0.43 & $-0.7(-1.8,0.3)$ & 0.18 & $-1.0(-2.0,0.0)$ & 0.047 \\
\hline uACR $>1,000 \mathrm{mg} / \mathrm{g} \mathrm{Cr}$ & $-5.5(-10.6,-0.1)$ & 0.045 & $-11.0(-17.5,-3.9)$ & 0.003 & $-13.2(-19.6,-6.3)$ & 0.0003 \\
\hline Hemoglobin (per g/dL increment) & $1.1(-0.3,2.4)$ & 0.13 & $-1.5(-3.3,0.3)$ & 0.11 & $-0.3(-2.3,1.7)$ & 0.75 \\
\hline $\begin{array}{l}\text { Serum albumin (per } 0.5 \mathrm{~g} / \mathrm{dL} \\
\text { increment) }\end{array}$ & $0.5(-2.3,3.2)$ & 0.75 & $3.7(-0.1,7.7)$ & 0.06 & $8.3(5.8,10.9)$ & $<0.0001$ \\
\hline $\begin{array}{l}\text { Serum iron (per } 25 \mu \mathrm{g} / \mathrm{dL} \\
\text { increment) }\end{array}$ & $0.6(-1.4,2.7)$ & 0.55 & $4.1(0.5,7.7)$ & 0.03 & $4.8(2.2,7.4)$ & 0.0003 \\
\hline $\begin{array}{l}\text { Transferrin saturation (per 10\% } \\
\text { increment) }\end{array}$ & $-0.2(-2.1,1.8)$ & 0.86 & $3.6(0.6,6.7)$ & 0.02 & $3.0(0.8,5.3)$ & 0.007 \\
\hline
\end{tabular}

Estimates are derived from linear regression of the log-transformed biomarker on the listed covariate, adjusted for mean CGM glucose. Difference entries are the percent difference in the alternative marker of glycemia per difference in the listed covariate when additionally adjusting for mean CGM glucose. Analyses exclude one participant with an implausible $\mathrm{HbA}_{1 \mathrm{c}}$-to-mean $\mathrm{CGM}$ glucose relationship. $\mathrm{Cr}$, creatinine.

manuscript for intellectual content. A.D. acquired data and critically reviewed the manuscript for intellectual content. D.L.T. and I.B.H. interpreted data, conceived and designed the study, and critically reviewed the manuscript for intellectual content. I.H.d.B. conceived and designed the study, analyzed and interpreted data, and wrote the manuscript. L.R.Z. and I.H.d.B. are the guarantors of this work and, as such, had full access to all the data in the study and take responsibility for the integrity of the data and the accuracy of the data analysis.

Prior Presentation. Parts of this study were presented at the 77th Scientific Sessions of the American Diabetes Association, San Diego, CA, 9-13 June 2017.

\section{References}

1. Welsh KJ, Kirkman MS, Sacks DB. Role of glycated proteins in the diagnosis and management of diabetes: research gaps and future directions. Diabetes Care 2016;39:1299-1306 2. Vos FE, Schollum JB, Coulter CV, Manning PJ, Duffull SB, Walker RJ. Assessment of markers of glycaemic control in diabetic patients with chronic kidney disease using continuous glucose monitoring. Nephrology (Carlton) 2012;17:182188

3. Peacock TP, Shihabi ZK, Bleyer AJ, et al. Comparison of glycated albumin and hemoglobin $A(1 c)$ levels in diabetic subjects on hemodialysis. Kidney Int 2008;73:1062-1068

4. English E, Idris I, Smith G, Dhatariya $K$ Kilpatrick ES, John WG. The effect of anaemia and abnormalities of erythrocyte indices on HbA1c analysis: a systematic review. Diabetologia 2015;58:1409-1421

5. Tarim $O$, Küçükerdoğan $A$, Günay U, Eralp $O$, Ercan I. Effects of iron deficiency anemia on hemoglobin $\mathrm{A} 1 \mathrm{C}$ in type 1 diabetes mellitus. Pediatr Int 1999;41:357-362

6. Rasche FM, Ebert T, Beckmann J, et al. Influence of erythropoiesis-stimulating agents on $\mathrm{HbA1C}$ and fructosamine in patients with haemodialysis. Exp Clin Endocrinol Diabetes 2017; 125:384-391

7. Thomas MC, Maclsaac RJ, Tsalamandris C, Power $D$, Jerums $G$. Unrecognized anemia in patients with diabetes: a cross-sectional survey. Diabetes Care 2003;26:1164-1169

8. Parrinello CM, Sharrett AR, Maruthur NM, et al. Racial differences in and prognostic value of biomarkers of hyperglycemia. Diabetes Care 2016;39:589-595

9. Bergenstal RM, Gal RL, Connor CG, et al.; T1D Exchange Racial Differences Study Group. Racial differences in the relationship of glucose concentrations and hemoglobin A1c levels. Ann Intern Med 2017;167:95-102

10. Carson AP, Muntner P, Selvin E, et al. Do glycemic marker levels vary by race? Differing results from a cross-sectional analysis of individuals with and without diagnosed diabetes. BMJ Open Diabetes Res Care 2016;4:e000213

11. Danese E, Montagnana M, Nouvenne A, Lippi $G$. Advantages and pitfalls of fructosamine and glycated albumin in the diagnosis and treatment of diabetes. J Diabetes Sci Technol 2015;9:169176

12. Zendjabil M. Glycated albumin. Clin Chim Acta 2020;502:240-244

13. Chen $C W$, Drechsler $C$, Suntharalingam $P$, Karumanchi SA, Wanner C, Berg AH. High glycated albumin and mortality in persons with diabetes mellitus on hemodialysis. Clin Chem 2017;63:477-485

14. Selvin E, Rawlings AM, Lutsey PL, et al. Fructosamine and glycated albumin and the risk of cardiovascular outcomes and death. Circulation 2015;132:269-277

15. Selvin E, Rawlings AM, Grams M, et al. Fructosamine and glycated albumin for risk stratification and prediction of incident diabetes and microvascular complications: a prospective cohort analysis of the Atherosclerosis Risk in Communities (ARIC) study. Lancet Diabetes Endocrinol 2014;2:279-288

16. Ding N, Kwak L, Ballew SH, et al. Traditional and nontraditional glycemic markers and risk of peripheral artery disease: the Atherosclerosis Risk in Communities (ARIC) study. Atherosclerosis 2018;274:86-93

17. Lee SY, Chen YC, Tsai IC, et al. Glycosylated hemoglobin and albumin-corrected fructosamine are good indicators for glycemic control in peritoneal dialysis patients. PLoS One 2013;8: e57762

18. Zheng CM, Ma WY, Wu CC, Lu KC. Glycated albumin in diabetic patients with chronic kidney disease. Clin Chim Acta 2012;413:1555-1561

19. Chen HS, Wu TE, Lin HD, et al. Hemoglobin $A(1 c)$ and fructosamine for assessing glycemic control in diabetic patients with CKD stages 3 and 4. Am J Kidney Dis 2010;55:867-874 20. Freedman BI, Shenoy RN, Planer JA, et al. Comparison of glycated albumin and hemoglobin A1c concentrations in diabetic subjects on peritoneal and hemodialysis. Perit Dial Int 2010;30: 72-79

21. Freedman BI, Shihabi ZK, Andries L, et al. Relationship between assays of glycemia in diabetic subjects with advanced chronic kidney disease. Am J Nephrol 2010;31:375-379

22. Ahmad I, Zelnick LR, Batacchi Z, et al. Hypoglycemia in people with type 2 diabetes and CKD. Clin J Am Soc Nephrol 2019;14:844853 
care.diabetesjournals.org

Zelnick and Associates

2387

23. Bergenstal RM, Beck RW, Close $K L$, et al. Glucose management indicator (GMI): a new term for estimating $\mathrm{A} 1 \mathrm{C}$ from continuous glucose monitoring. Diabetes Care 2018;41:2275-2280 24. Inter LA, Schmid CH, Tighiouart H, et al.; CKD$\mathrm{EPI}$ Investigators. Estimating glomerular filtraton rate from serum creatinine and cystatin C. N Eng J Med 2012;367:20-29

25. Fisher RA. Frequency distribution of the values of the correlation coefficient in samples from an indefinitely large population. Biometrika 1914;10:507-521

26. White H. A heteroskedasticity-consistent covariance-matrix estimator and a direct test for heteroskedasticity. Econometrical 1980;48: 817-838

27. Cohen S, Freeman T. Metabolic heterogeneity of human gamma-globulin. Biochem J 1960; 76:475-487

28. Lo C, tui M, Ranasinha S, et al. Defining the relationship between average glucose and $\mathrm{HbA} 1 \mathrm{c}$ in patients with type 2 diabetes and chronic kidney disease. Diabetes Res Clin Pact 2014;104:84-91 29. Joke RA, McAlister JM, Prankerd TAJ. Isotope investigations of red cell production and destruction in chronic renal disease. Olin Sci 1956;15:511-522
30. Nakao T, Matsumoto H, Okada T, et al. Influency of erythropoietin treatment on hemoglobin Ac levels in patients with chronic renal failure on hemodialysis. Intern Med 1998;37:826-830 31. Besarab A, Bolton WK, Browne JK, et al. The effects of normal as compared with low heratcrit values in patients with cardiac disease who are receiving hemodialysis and epoetin. N Eng J Med 1998;339:584-590

32. Drüeke TB, Locatelli F, Clyne N, et al.; CREATE Investigators. Normalization of hemoglobin level in patients with chronic kidney disease and anemia. N Eng J Med 2006;355:2071-2084

33. Pfeffer MA, Burdmann EA, Chen CY, et al.; TREAT Investigators. A trial of darbepoetin alfa in type 2 diabetes and chronic kidney disease. $\mathrm{N}$ Eng J Med 2009;361:2019-2032

34. Singh AK, Szczech L, Tang KL, et al.; CHOIR Investigators. Correction of anemia with epoetin alfa in chronic kidney disease. N Eng J Med 2006; 355:2085-2098

35. Kaysen GA, Gambertoglio J, Felts J, Hutchison FN. Albumin synthesis, albuminuria and hyperlipemia in nephrotic patients. Kidney Int 1987;31:1368-1376

36. Levitt DG, Levitt MD. Human serum albumin homeostasis: a new look at the roles of synthesis, catabolism, renal and gastrointestinal excretion, and the clinical value of serum albumin measuremints. Int J Gen Med 2016;9:229-255

37. Selvin E, Warren B, He X, Sacks DB, Saenger AK. Establishment of community-based reference intervals for fructosamine, glycated albumin, and 1,5-anhydroglucitol. Chin Chem 2018; 64:843-850

38. Jung $M$, Warren B, Grams $M$, et al. Performance of nontraditional hyperglycemia biomarkers by chronic kidney disease status in older adults with diabetes: results from the Atherosclerosis Risk in Communities Study. J Diabetes 2018;10:276-285

39. Hayashi A, Takano K, Masai T, Yoshino S, Ogawa A, Shichiri M. Distinct biomarker roles for $\mathrm{HbA}_{1 \mathrm{c}}$ and glycated albumin in patients with type 2 diabetes on hemodialysis. J Diabetes Complications 2016;30:1494-1499 40. Afkarian M, Zelnick LR, Hall YN, et al. Clinical manifestations of kidney disease among US adults with diabetes, 1988-2014. JAMA 2016; 316:602-610

41. Bane T, Nimbi R, Battelino $T$, et al. International consensus on use of continuous glucose monitoring. Diabetes Care 2017;40: 1631-1640 